University of Wollongong

Research Online

Faculty of Social Sciences - Papers (Archive) Faculty of Arts, Social Sciences \& Humanities

$1-1-2019$

State of the art in U.S. multicultural social work practice: Client

expectations and provider challenges

Katarzyna J. Olcon

University of Wollongong, kolcon@uow.edu.au

Follow this and additional works at: https://ro.uow.edu.au/sspapers

Part of the Education Commons, and the Social and Behavioral Sciences Commons

Research Online is the open access institutional repository for the University of Wollongong. For further information contact the UOW Library: research-pubs@uow.edu.au 


\title{
State of the art in U.S. multicultural social work practice: Client expectations and provider challenges
}

\author{
Abstract \\ To obtain a comprehensive view of the level of knowledge and development achieved in multicultural \\ social work practice, I conducted a scoping review of U.S. empirical literature for the 10-year period from \\ 2007 through 2016. The review revealed that across the board racial and ethnic minority clients continue \\ to experience marginalization and report low satisfaction with services. Conversely, providers are subject \\ to some tensions and biases toward multicultural practice exacerbated by employers' lack of emphasis \\ on cultural competence. The problematic findings from the review suggest that our current approaches to \\ cultural competence may need to be reexamined.

\section{Disciplines} \\ Education | Social and Behavioral Sciences

\section{Publication Details} \\ Olcon, K. (2019). State of the art in U.S. multicultural social work practice: Client expectations and \\ provider challenges. Journal of Ethnic and Cultural Diversity in Social Work: innovations in theory, \\ research and practice, 28 (1), 7-30.
}


State of the Art in the U.S. Multicultural Social Work Practice:

Client Expectations and Provider Challenges

Katarzyna Olcoń

University of Wollongong, Australia

Author: Katarzyna Olcoń, PhD, MSW, Lecturer, Social Work, School of Health and Society, Faculty of Social Sciences, University of Wollongong, South Western Sydney Campus, 33 Moore St, Liverpool, NSW 2170, Australia. Email: kolcon@uow.edu.au 


\begin{abstract}
To obtain a comprehensive view of the level of knowledge and development achieved in multicultural social work practice, I conducted a scoping review of U.S. empirical literature for the ten-year period from 2007 through 2016. The review revealed that across the board racial and ethnic minority clients continue to experience marginalization and report low satisfaction with services. Conversely, providers are subject to some tensions and biases toward multicultural practice exacerbated by employers' lack of emphasis on cultural competence. The problematic findings from the review suggest that our current approaches to cultural competence may need to be re-examined.
\end{abstract}

Keywords: multicultural social work, culture, cultural competence, diversity, social service providers, client satisfaction 
State of the Art in the U.S. Multicultural Social Work Practice:

Client Expectations and Provider Challenges

\section{Introduction}

In the United States, social work providers and other helping professionals, such as counselors or youth workers, frequently work with clients who come from a variety of racial and ethnic backgrounds. There is consensus in the literature that service providers' ability to work across cultural differences is important for racial and ethnic minority clients (Sue, Rasheed, \& Rasheed, 2015). According to Wilkinson-Lee, Russell, and Lee (2006), service providers play a crucial role because "[they] are the individuals who shape the cultural sensitivity of any prevention program on a daily basis in their professional lives" (p. 385). Thus, the social worker's beliefs, values, worldviews, and ways of knowing are an essential component in the efforts to provide authentically culturally sensitive and relevant social services.

Despite educational preparation on cultural competence (CSWE, 2015) and ethical requirements (NASW, 2017), a look at the literature on minority client outcomes suggests gaps in the translation to practice. Racial and ethnic minority individuals are less likely, for example, to receive high quality mental health care (McGuire \& Miranda, 2008), substance abuse treatment (Guerrero, Marsh, Khachikian, Amaro, \& Vega, 2013), and referrals to social services from the juvenile justice system (Spinney et al., 2016). In a comprehensive overview of the issues African Americans face in mental health services, Briggs, Briggs, Miller, and Paulson (2011) detailed the many institutional inequalities and cultural insensitivities, such as lack of minority representation among mental health professionals, that result in underutilization of services.

Few efforts have been made to synthesize a body of knowledge related to multicultural 
social service provision. A major "state of the art" work was offered by Schlesinger and Devore (1995), where the authors reviewed ten-years of literature on ideological, theoretical, \& practice issues related to ethnic-sensitive social work practice. In a more recent work, Kohli, Huber, and Faul, (2010) provided a detailed summary of the historical and theoretical development of culturally competent social work practice. No review has been conducted, however, of the empirical evidence as related to cultural competence of social service providers and the satisfaction and experiences of service recipients of racial and ethnic minority groups.

To address this gap and to obtain a comprehensive view of the level of knowledge and development achieved in multicultural social work practice, I take stock of the evidence from existing research. The results are presented from a scoping review of empirical literature that assessed the outcomes and experiences with multicultural practice of racial and ethnic minority clients and social work providers. Examining the perspectives of both clients and providers allows for a comprehensive profile of the current state of the art and provides a useful framework for analysis. Together, consumer perspectives and provider first-hand accounts of the challenges that arise in the provision of care can help us generate patient- and client-centered and culturally relevant practices (Carpenter-Song, Schwallie, \& Longhofer, 2007). The aim of the study is to inform ways to better meet the needs of historically excluded racial and ethnic groups and to critically evaluate the impact of theoretical foundations and principles of cultural competence in the field.

\section{Conceptualizing Multiculturalism and Culture}

The concept of multicultural practice is extensive and includes many groups, such as women, racial and ethnic groups, LGBT individuals, people with disabilities, religious minorities, and others (Sue, Rasheed, \& Rasheed, 2015). The focus of this article is on racial and 
ethnic diversity only in social service provision in the United States. Practice with culturally diverse populations is influenced by different epistemologies that guide the way culture is conceptualized (Williams, 2006). From the critical perspective, culture is viewed as a tool of power of one group over another (e.g., Williams, 2006). This definition of culture has been widely embraced in some parts of the world, such as Latin America, which has been more critical of oppressive power structures (Freire, 1970). In the United States, the literature of helping professions, such as social work, tends to portray culture predominantly in terms of values, beliefs, customs, and acculturation, frequently overseeing the socio-historical context of the clients, particularly economic disparities. According to Viruell-Fuentes, Miranda, and Abdulrahim (2012) from this perspective culture tends to be essentialized and pathologized and is used as a tool to obscure structural barriers and limited life opportunities.

The conceptualization of culture that guides this article integrates both structural context and individual worldviews based on Taylor's definition of culture as "the story of the person" that is "what people think and say, and what they have experienced" (2003, p. 177). This definition implies that culture is the entirety of person's lived experience, which includes but is not limited to one's worldviews, values and behaviors. An important aspect of "the story of the person" is his or her life context and life opportunities, which are always shaped by power dynamics and social structures.

\section{Methods}

The purpose of this scoping review was to provide a synthesis of empirical literature on racial and ethnic minority clients and social service providers, in terms of their expectations, experiences, outcomes, and challenges in multicultural social service encounters. The scoping review method allows for addressing a broad topic based on the analyses of studies using a 
variety of designs and without restrictions based on quality indicators (Arksey \& O’Malley, 2005; Levac, Colquhoun, \& O’Brien, 2010).

The scoping review covered research studies conducted in the United States in the tenyear period from 2007 through 2016. Inclusion criteria for client studies were as follows: 1) satisfaction and/or experiences of racial and ethnic minority clients in multicultural services; 2) health and social services settings, such as child welfare, mental health, and substance abuse treatment and; 3) social workers and other helping professionals. This criterion allowed for capturing the experiences of clients in typical service settings, which require client interactions with a range of professionals. In terms of the studies on service providers, inclusion criteria were as follows: 1) providers' levels of cultural competence and factors associated with it; 2) providers' experiences in working with racial and ethnic minority clients; and 3) health and social service settings.

Original research studies were reviewed separately and the results mapped out for each of the two study groups, clients and providers. Research citations were searched in Social Service Abstracts, PsycINFO, Academic Search Complete, PubMed, and Web of Science with the combination of search terms such as "social worker*" "social work provider*", race, cultur*, multicultur*, divers*, “client satisfaction”, empirical, qualitative, and quantitative. After identification of relevant articles, the references of each article were hand searched for other studies that fit the inclusion criteria.

\section{Results}

A total of 23 studies met the inclusion criteria for the client group (see Table 1) and 26 for the providers group (see Table 2). The client studies included 11 quantitative and 11 qualitative studies, and one mixed methods study. Among the providers studies, 12 were 
qualitative, 12 were quantitative, and 2 were mixed methods. In total, 12 of the studies were doctoral dissertations, and two were master's theses. All others were reported in peer-reviewed articles. The findings of the scoping review are synthesized below, beginning with the guiding theories and methods utilized and the characteristics of the sample of studies included in the analysis. The factors affecting racial and ethnic minority client satisfaction and the provider experience in terms of achieving cultural competence are then summarized.

\section{Guiding Theories and Methods}

One of the most frequently utilized theoretical frameworks to guide the research studies on multicultural practice for both clients and providers was the cultural competence model. Some of the other guiding theories included social constructionist theory, critical race theory, and the White Racial Identity Development Model (Helms, 1984). The majority of the studies, however, did not specify their theoretical grounding. Some cited literature on concepts such as multiculturalism, racism, social justice, racial disparities in health and health care, or bilingual and bicultural human service provision.

The sample in the clients' studies ranged from 8 to 210 in the qualitative studies, 24 to 5,002 in the quantitative studies, and 83 in the mixed method study. Participants were mostly racial and ethnic minority clients, although several of the quantitative studies included White clients and analyzed the results by comparing the outcomes for the different groups. Some studies used national datasets while others recruited participants through local mental health organizations, hospitals, and social service facilities.

In the providers' studies, the samples ranged from 6 to 56 in the qualitative studies, 81 to 1,124 in the quantitative studies, and 29 to 256 in the mixed method studies. The participants were frequently recruited through regional and national social work organization listservs such as 
Council on Social Work Education and the National Association of Social Workers. The majority of the studies involved predominantly White samples, and only few studies had a relatively equal representation of different racial and ethnic groups (e.g., Stampley, 2008). Some studies focused specifically on White social workers (e.g., Davis, 2012; Loya, 2011), while others looked only at social workers of one racial or ethnic minority group (e.g., Thomas, Medina, \& Cohen, 2010).

The research design in the qualitative and mixed methods studies involved individual interviews, focus groups, or both. A few of the studies specified their methodological approach, including phenomenology, grounded theory, or thematic analysis; however, most of the studies did not provide this information. All of the quantitative studies were cross-sectional and based on surveys. Some of the measures used in the clients' studies included: the Client Cultural Competence Inventory (CCCI; Switzer, Scholle, Johnson, \& Kelleher, 1998), the ConsumerBased Cultural Competence Inventory (CBCCI; Cornelius, Booker, Arthur, Reeves, \& Morgan, 2004), the Racial Microaggressions in Counseling Scale (RMCS; Constantine, 2007), and the Cultural Mistrust Inventory (CMI; Terrell \& Terrell, 1981). In the providers' studies, some of the scales used were: the Personal and Professional Beliefs about Diversity Scale (Pohan \& Aguilar, 2001), the Scale of Ethnocultural Empathy (SEE; Wang, Davidson, Yakushko, Savoy, Tan, \& Bleier, 2003), the White Racial Identity Attitude Scale (WRIAS; Helms \& Carter, 2002), the Multicultural Counselor Knowledge and Awareness Scale (MCKAS; Ponterotto, Gretchen, Utsey, Rieger, \& Austin, 2002), the Color-Blind Racial Attitudes Scale (CoBRAS; Neville, Lilly, Duran, Lee, \& Browne, 2000), and the Cultural Competence Self-Assessment Questionnaire (CCSAQ; Mason, 1995).

\section{The Client Experience: Factors Affecting Satisfaction}


This section discusses the findings from the empirical literature on the satisfaction, experiences, outcomes and needs of racial and ethnic minority clients in health and human services. First, the studies explored minority clients' experiences of marginalization and discrimination in services and the implications of these experiences. Second, they looked at the relationship between providers' cultural competence (usually as perceived by clients) and the clients' satisfaction with services and their treatment outcomes. Finally, the studies explored the topic of cross-racial service provision and racial matching.

Clients' experiences of discrimination. The studies revealed that racial and ethnic minority clients faced numerous barriers when accessing health, human, and social services. Often, providers did not adequately address the needs of minority communities (e.g., Ahn, Miller, Wang, \& Laszloffy, 2014; Barrio, et al., 2008; Holley, Tavassoli, \& Stromwall, 2016). For example, in describing the experiences of migrant parents of children in mandated therapy, Ahn et al. (2014) reported that all participants felt discriminated against and devalued by a larger system that "led to feelings of inferiority in comparison to Americans" (Ahn et al., 2014, p. 33). Racial and ethnic minority clients reported having experienced marginalization, discrimination, bias, and microaggressions from social workers and other professionals in healthcare services (Black, 2012; Hicks, Tovar, Orav, \& Johnson, 2008), mental health services (Constantine, 2007; Holley et al., 2016; Huang, Appel, \& Ai, 2011; Lorenzo-Blanco \& Delva, 2012), and substance abuse services (Jones, Hopson, Warner, Hardiman, \& James, 2015). Constantine (2007) found 12 different types of microaggressions that African American college students experienced while receiving college counseling services. Providers accused the clients of hypersensitivity regarding racial or cultural issues, denied racial-cultural differences through colorblind statements, and denied their personal racism. Holley, et al. (2016) found that minority clients felt disregarded in 
mental health services. They reported often having their identities simplified and rights disrespected and being perceived as lacking intelligence.

Not surprisingly, the experiences of discrimination decreased clients' satisfaction with services (Huang et al., 2011), perceived treatment helpfulness (Lorenzo-Blanco \& Delva, 2012), and trust in both service providers and the treatment methods (Delphin-Rittmon, et al., 2013; Jones et. al., 2015; Scott, McCoy, Munson, Snowden, \& McMillen, 2011). A study of Latino clients, for example, revealed that they were reluctant to seek mental health services because they feared racism or the possibility of being culturally misunderstood (Rastogi, MasseyHastings, \& Wieling, 2012).

\section{Client satisfaction and outcomes and provider's level of cultural competence. The} studies consistently showed a positive relationship between provider's level of cultural competence and minority client satisfaction with health, human, and social services (e.g., Damashek, Bard, \& Hecht, 2012; Kraft, 2011). For example, a strong positive relationship was found between providers' level of cultural competence and client satisfaction with mental health services (Kraft, 2011; Mancoske, Lewis, Bowers-Stephens, \& Ford, 2012), child welfare services (Damashek et al., 2012; Scott, et al., 2011), and elderly home visit services (Reddick \& Eller, 2013). Moreover, providers' level of cultural competence predicted better client outcomes (Damashek et al., 2012; Hook, Davis, Owen, Worthington Jr, \& Utsey, 2013; Mancoske et al., 2012; Michalopoulou, et al., 2014). For example, there was a positive link between the clients' perception of providers' cultural competence and clients' improvements in social interactions, performance at work or school, and in managing life problems (Michalopoulou et al., 2014).

Various mechanisms seemed to be at play in the relationship between providers' cultural competence and client satisfaction and outcomes. For example, Hook et al. (2013) found that the 
positive relationship between providers' level of cultural humility and clients' improvement in therapy is mediated by a strong working alliance. Conversely, the lack of cultural competence in providers created a barrier for participants in a substance abuse program to develop trust and engage in long-term therapeutic relationships (Jones et al., 2015). Clients also sometimes referred to cultural competence by describing a provider's characteristics and the working environment they created. For example, Latino clients preferred providers who were warm, and “connected" with their patients (Rastogi et al., 2012). Similarly, African American clients reported a desire for connectedness with healthcare professionals as expressed by being listened to and having an authentic conversation (Black, 2012). White clients were most likely to rate the providers at the highest level of cultural competence, and Latino and Black clients were least likely to report that it was "easy to talk to" providers and that they were being listened to carefully (Pardasani \& Bandyopadhyay, 2014). Finally, providers' cultural competence was found to increase openness to counseling services among Black and Hispanic male victims of community violence (Lawrence, 2011) and to positively influence the perception of mental health services by migrant parents whose children were mandated to receive treatment services (Ahn et al., 2014).

Client satisfaction with cross-racial service provision. Several studies investigated the implications of cross-racial services and racial matching for minority clients with inconsistent results. Mancoske et al., (2012) found that ethnic or racial match did not influence clients' perceptions of service providers' cultural competence. On the other hand, African Americans and Hispanic social service recipients reported that having a provider of the same race/ethnicity was very important to them (Hsu, Hackett, \& Hinkson, 2014). Cultural similarity was found to facilitate the development of trust in mental health providers which in turn increased the 
satisfaction with services (Delphin-Rittmon et al., 2013). Another study showed that ethnic match predicted treatment goal completion in child welfare services for non-White participants (Damashek et al., 2012).

Minority clients also took notice of the shortage of providers who represent their communities. For example, African Americans viewed the mental health and health care system as staffed predominantly by middle and upper-class Whites, creating barriers to communication and feelings of marginalization and alienation (Newhill \& Harris, 2007). African American clients also noted that when working with a White provider they did not discuss race or racerelated issues, and they had never been asked about racial issues or their community (DelphinRittmon et al., 2013). In the words of one of the participants: “...you can talk to your therapist about a lot of things, but when it comes to a race issue, then that's taboo" (Delphin-Rittmon et al., 2013, p. 148). Similarly, Jones et al., (2015) found that African American clients felt that providers tend to generalize black people and ignore issues of race in counseling.

Chang and Berk (2009) found that half of 16 racial and ethnic minority clients who received treatment from 16 different White therapists reported a satisfying experience and half did not. They found that although cultural competence was important for these clients (evident through warmth and caring, self-disclosure, and a more directive therapeutic style), acts of cultural incompetence (minimizing the realities of racial minorities and being guided by stereotypes) were detrimental for the relationship. In a similar manner, African American clients' experiences of racial microaggressions decreased their therapeutic alliance and satisfaction with White therapists and predicted lower ratings of the providers' general and cultural counseling competence (Constantine, 2007).

\section{The Provider Experience: Achieving Competence}

This section summarizes the findings from the studies on the provider experiences in 
multicultural practice. The studies reviewed took different approaches to the challenges of social work providers in multicultural practice. Some examined providers' level of cultural competence and their understanding of the concept. Others analyzed the providers' experiences in working with racially and ethnically diverse clients. Finally, others explored factors that promote (e.g., diversity courses) or inhibit (e.g., White privilege and unequal power dynamics) culturally sensitive practice.

In most cases, providers demonstrated a commitment to culturally competent services to better serve clients (e.g., Graham, Shier, \& Brownlee, 2012; Lanesskog, Piedra, \& Maldonado, 2015). Graham et al. (2012) found that providers working with diverse populations were always trying to adapt social work theories and practice models to meet the needs of diverse communities. Indeed, Garran (2008) reported that higher clinician abilities related to cultural competence, racial identity, and ethnocultural empathy were associated with a better therapeutic engagement with at risk, urban youth of color. Two studies focused on the perspectives on culture competence specifically among White social workers. Davis (2012) found that White social workers' definitions of cultural competence were consistent with the NASW cultural standards. They believed cultural competence to be an active, intentional, and lifelong process (Davis, 2012). Davis and Gentlewarrior (2015) additionally found that White social workers believed that self-awareness about racism and White privilege are key to effective clinical work.

Levels of cultural competence of social work providers. Levels of cultural competence in the reviewed studies ranged from good (Joseph, Slovak, Broussard, \& Webster, 2012) to moderate (Richardson, 2008; Teasley, Archuleta, \& Miller, 2014) to poor (Brumfield, 2013), based largely on self-reports. In some cases, the same provider scored high on one component of cultural competence - showing good levels of culturally sensitive values and self-awareness, for 
example - yet had a limited knowledge and skills related to multicultural practice (Williams, Nichols, \& Williams, 2013). In a study of over 300 school social workers from the Midwest, Joseph et al. (2012) found that more than $90 \%$ of the sample of providers reported that they worked to ensure school policies and practices were informed by the principle of cultural proficiency by influencing school culture, speaking up when they saw unintentional discrimination, and taking advantage of teachable moments to share cultural knowledge. Using a model of the stages of change for coping and responding to racism and oppression as a gauge, Phillips (2010) found that social workers were fairly good at recognizing racism and oppression. Half were in the "maintenance" stage of coping/responding to racism, and $22 \%$ were in either the pre-contemplation or contemplation stage.

Some differences were found in levels of cultural competence based on the race and ethnicity of social workers and on geographic location. One study revealed that African American school social workers had higher levels of perceived cultural competence (Teasley, et al., 2014). A second study showed that non-White social workers were on average in a more advanced stage of change for actively coping with racism and/or oppression than were Whites (Phillips, 2010). Finally, Stampley (2008) found that White social workers experienced particular discomfort in asking minority clients questions that reflected cultural transference such as family lineage relationships and parentage. Geographic location of practice was also found to be a significant predictor of cultural competence. Urban and inner-city school social workers scored significantly higher on cultural competence compared to those from suburban and rural service areas (Teasley et al., 2014).

Areas of providers' struggles and tensions in multicultural practice. Several studies exposed providers' struggles, tensions, and biases with multicultural practice (e.g., Horton, 2015; 
Stampley, 2008). Focusing on the concept of cultural countertransference, McCoy (2008) found that in many cases where there was a cultural difference between a clinical social worker and the client, the clinician was less comfortable, overly curious, or irritated. This frequently led to clients prematurely discontinuing therapy services. Similarly, Stampley (2008) found several manifestations of cultural transference in social work providers, including difficulties identifying clients' strengths and life achievements and holding myths and stereotypes about clients. This led providers to distance themselves and avoid certain clients as well as to apply their own cultural beliefs and values to guide client assessments and to manage the therapeutic relationship.

Another area of tension and bias for providers was related to White privilege, namely issues of power and the promotion of mainstream values. For example, in a study of White family case managers, Horton (2015) found that most accepted the problematic theory of culture of poverty, believing that all Americans have equal opportunities in life and that hard work would allow parents involved with the child welfare system to raise themselves out of poverty. Similarly, Loya (2011) found a limited awareness of racial privilege as well as "blatant racial issues" (p. 201) among White social workers, who expressed beliefs such as that "talking about race issues causes unnecessary tensions" (p. 208). White child welfare workers were less likely than African American workers to believe that race should be considered both in child foster and adoptive home placement decisions (Jayaratne, Faller, Ortega, \& Vandervort, 2008). Another study showed that Native American social workers felt silenced and powerless and perceived White child welfare workers as misunderstanding the Native culture (Bubar \& Bundy-Fazioli, 2011). Yet, other studies showed that White providers acknowledged that White privilege has an important impact on multicultural service provision. For example, according to Davis and Gentlewarrior (2015), White providers believed it was important to address White privilege in 
clinical conversations as well as initiate anti-racist work in their own circles.

Factors promoting and inhibiting culturally sensitive practice. Several studies examined factors (e.g., personal, educational, professional, and structural) that affected providers' levels of cultural competence (e.g. Bragg, 2010; Davis, 2012). Personal experiences, such as having immigrated to the United States from another country (Baranowski, 2015; Davis, 2012), were associated with providers' cultural sensitivity as was having relationships with people from racial-ethnic and cultural groups other than their own (Larrison, Schoppelrey, HackRitzo, \& Korr, 2011). Moreover, providers’ professional beliefs about cultural competence reflected their personal beliefs about the topic according to a study by Bragg (2010). Personal beliefs were measured with the Personal Beliefs about Diversity Scale which includes questions such as "It is more important for immigrants to learn English than to maintain their first language" and "Accepting many different ways of life in America will strengthen us as a nation" (Bragg, 2010, p. 58).

Cultural competence levels were also affected by education and professional training (e.g., Richardson, 2008). Providers who completed cultural competence trainings and courses were more likely to have higher levels of cultural competence (Davis, 2012; Grant, 2008; Richardson, 2008; Teasley et al., 2014; Teasley, Gourdine, \& Canfield, 2010) than were those who did not. Bragg (2010) found, however, that although those who received cultural competence education believed they had higher cultural competence skills, their personal beliefs about diversity, such as negative stereotypes and prejudices, were not impacted. Moreover, BSW-level practitioners were less aware of racial privilege and blatant racial issues than were those who held an MSW (Loya, 2011). Unlike targeted cultural competence education, some studies found that providers did not feel their social work education had adequately prepared 
them for practice with diverse groups (Bhuyan, Park, \& Rundle, 2012; Graham et al., 2012). For example, only 22 percent of a nationally representative sample of social work providers believed they had sufficient knowledge of immigrant issues, and the majority reported that the coursework in social work education on practice with immigrants did not impact their attitudes or knowledge in this area (Bhuyan et al., 2012).

Another major influence on providers' levels of cultural competence were structural barriers. These included: lack of resources in settings that serve multicultural populations (Baranowski, 2015; Jones, 2012), institutional racism in work settings (Loya, 2011; Parker, 2014), employers' lack of recognition of multicultural skills (Thomas et al., 2010), and little awareness of multicultural issues in interdisciplinary teams (Teasley et al., 2010). Joseph et al., (2012) reported that school social workers' level of activities in promoting multiculturalism were affected by schools' active policies to address diversity and multiculturalism. When they worked with institutions and colleagues whom they perceived as indifferent to the needs of diverse clients (Latino immigrants, for example), workers who possessed qualities of cultural and language competence felt frustrated, isolated, and dissatisfied (Lanesskog et al., 2015). Providers also reported a general shortage of culturally appropriate services and providers (Bubar \& Bundy-Fazioli, 2011; Thomas et al., 2010) and stressed the need for language skills (Baranowski, 2015; Lanesskog et al., 2015). Structural barriers affected providers' sense of professional effectiveness. One study found that the inability of social workers to meet the needs of their undocumented immigrant clients made them feel that they were working "against the grain," which led to frustration and emotional exhaustion (Jones, 2012, p. 47).

\section{Discussion}

In the context of cultural competence standards and a concern for effective client- 
centered practice, culture has become an important component of the discourse on social work practice. This scoping review synthesized U.S.-based empirical studies from 2007 to 2016 that investigated the topic of cultural competence and multicultural practice among social service recipients and service providers. By conducting reviews for both groups, part of the aim was to bring to light the experiences of clients vis-à-vis providers.

The scoping review revealed that provider's cultural competence was a critical component of racial and ethnic minority client satisfaction. Many racial and ethnic minority clients reported having experienced marginalization, discrimination, bias, and microaggressions from social workers and other helping professionals. At the same time, the setting where the providers worked frequently seemed to ignore or even perpetuate these negative client experiences. Structural barriers to culturally sensitive services involved different manifestations of institutional racism, little knowledge and awareness of multicultural issues, lack of resources in settings that serve diverse populations, and employers' lack of recognition of multicultural skills. On a personal level, although committed to cultural competence, some providers experienced tensions and biases in multicultural practice often related to privilege and power dynamics, and often applied their own cultural beliefs and values to guide client assessments and interventions.

Although indicative, the findings from this scoping review should be interpreted cautiously due to the reliance of most of the reviewed studies on descriptive research design. All quantitative studies were cross-sectional, and they relied entirely on self-reports, which can be particularly prone to social desirability bias on the topic of racial and cultural diversity (Larson \& Bradshaw, 2017). Many of the studies also lacked theoretical grounding and clarity about the data analysis process. The design of reviewed studies thus limits the ability to make 
recommendations for practice. The study outcomes were informative in that they offered a wide range of cultural competence levels and experiences in multicultural practice across different settings. However, this further limits their ability to inform specific areas of practice.

Interestingly, of the 49 studies reviewed only 14 came from social work journals. The majority were published in journals such as the Community Mental Health Journal, Journal of Counseling Psychology, Journal of Child and Family Studies, and others. An important finding in itself is, therefore, that there are relatively few studies in the social work literature on the experiences of racial and ethnic minority clients with service providers.

There is a clear urgency to expand the empirical evidence regarding client satisfaction and social work providers' cultural competence as well as their experiences and challenges with multicultural service provision. A clear and comprehensive picture is needed of providers' experiences in multicultural practice and the factors that enhance and hinder effective service provision. Longitudinal, large-scale, and multisite studies are recommended in order to compare provider and client experiences in different contexts. Supplementary and more rigorous research methods, such as experimental and quasi-experimental designs and prolonged ethnographic observations are needed to complement studies based solely on cross-sectional and self-report measures. Thus, the application of more complex and rigorous methodological designs and stronger theoretical support will allow for a deeper understanding of this critical aspect of practice.

Notwithstanding, the problematic findings from our study suggest that our current approaches to cultural competence may need to be re-examined. As Timimi (2010) reminds: “As socially respected practitioners, we have a responsibility to understand that we bring a cultural value system to our work. Our actions will have effects in [the] wider local community" (p. 702). 
A critical analysis of the cultural value system that providers bring into the space of encounter with their clients, and how those reflect institutional and structural value systems and ideologies, may be thus required to ensure an authentic service provision to culturally diverse clients.

\section{References}

Ahn, Y., Miller, M., Wang, L., \& Laszloffy, T. (2014). 'I didn't understand their system, and I didn't know what to do': Migrant parents' experiences of mandated therapy for their children. Contemporary Family Therapy: An International Journal, 36(1), 25-40.

Arksey, H., \& O’Malley, L. (2005). Scoping studies: Towards a methodological framework. The International Journal of Social Research Methodology, 8(1), 19-32.

Baranowski, K. A. (2015). The experiences of mental health practitioners working with undocumented immigrants from Mexico along the U.S./Mexico border (Doctoral dissertation). Retrieved from ProQuest Dissertations \& Theses Global.

Barrio, C., Palinkas, L. A., Yamada, A. M., Fuentes, D., Criado, V., Garcia, P., \& Jeste, D. V. (2008). Unmet needs for mental health services for Latino older adults: Perspectives from consumers, family members, advocates, and service providers. Community Mental Health, 44(1), 57-74.

Bhuyan, R., Park, Y., \& Rundle, A. (2012). Linking practitioners' attitudes towards and basic knowledge of immigrants with their social work education. Social Work Education, 31(8), 973-994.

Black, H. K. (2012). The influence of African American elders' belief systems on health interactions. Journal of Religion \& Spirituality in Social Work, 31(3), 226-243.

Bragg, S. H. (2010). Mental health professionals' education and training effect on personal and professional beliefs with a culturally diverse population (Doctoral dissertation). 
Retrieved from ProQuest Dissertations \& Theses Global.

Briggs, H. E., Briggs, A. C., Miller, K. M., \& Paulson, R. I. (2011). Combating persistent cultural incompetence in mental health care systems serving African Americans. Best Practices in Mental Health, 7(2), 1-25.

Brumfield, P. W. (2013). Multicultural competence of school social workers within a South Atlantic state: Perspectives on training, demographics, and work performance (Doctoral dissertation). Retrieved from ProQuest Dissertations \& Theses Global.

Bubar, R., \& Bundy-Fazioli, K. (2011). Unpacking race, culture, and class in rural Alaska: Native and Non-Native multidisciplinary professionals' perceptions of child sexual abuse. Journal of Ethnic \& Cultural Diversity in Social Work, 20(1), 1-19.

Carpenter-Song, E. A., Schwallie, M. N., \& Longhofer, J. (2007). Cultural competence reexamined: Critique and directions for the future. Psychiatric Services, 58(10), 13621365.

Chang, D. F., \& Berk, A. (2009). Making cross-racial therapy work: A phenomenological study of clients' experiences of cross-racial therapy. Journal of Counseling Psychology, 56(4), $521-536$.

Constantine, M. G. (2007). Racial microaggressions against African American clients in crossracial counseling relationships. Journal of Counseling Psychology, 54(1), 1-16.

Cornelius, L.J., Booker, N.C, Arthur, T.E., Reeves, I., \& Morgan, O. (2004). The validity and reliability testing of a consumer-based cultural competency inventory. Research on Social Work Practice. 14(3) 201-208.

Council on Social Work Education [CSWE]. (2015). Educational Policy and Accreditation Standards. Retrieved from 
http://www.cswe.org/getattachment/Accreditation/Accreditation-Process/2015-

EPAS/2015EPAS_Web_FINAL.pdf.aspx

Damashek, A., Bard, D., \& Hecht, D. (2012). Provider cultural competency, client satisfaction, and engagement in home-based programs to treat child abuse and neglect. Child Maltreatment, 17(1), 56-66.

Davis, A. D. (2012). Process, power, and possibilities: An exploration of experienced White social workers' cultural competence in clinical practice (Doctoral dissertation). Retrieved from ProQuest Dissertations \& Theses Global.

Davis, A., \& Gentlewarrior, S. (2015). White privilege and clinical social work practice: Reflections and recommendations. Journal of Progressive Human Services, 26(3), 191208.

Delphin-Rittmon, M., Bellamy, C. D., Ridgway, P., Guy, K., Ortiz, J., Flanagan, E., \& Davidson, L. (2013). 'I never really discuss that with my clinician': U. S. consumer perspectives on the place of culture in behavioural healthcare. Diversity and Equality in Health and Care, $10(3), 143-154$.

Freire, P. (1970). Pedagogy of the oppressed. (M. B. Ramos, Trans.). New York, NY: Seabury. Garran, A. M. (2008). Cultural competence, racial identity, and ethnocultural empathy in therapeutic engagement with at risk, urban adolescents of color (Doctoral dissertation). Retrieved from ProQuest Dissertations \& Theses Global (AAI3339645).

Graham, J. R., Shier, M. L., \& Brownlee, K. (2012). Contexts of practice and their impact on social work: A comparative analysis of the context of geography and culture. Journal of Ethnic \& Cultural Diversity in Social Work: Innovation in Theory, Research \& Practice, 21(2), 111-128. 
Grant, C. M. (2008). Cultural competence: The role of cultural values in child welfare practice with African American families (Doctoral dissertation). Retrieved from ProQuest Dissertations \& Theses Global.

Guerrero, E. G., Marsh, J. C., Khachikian, T., Amaro, H., \& Vega, W. A. (2013). Disparities in Latino substance use, service use, and treatment: Implications for culturally and evidence-based interventions under health care reform. Drug and Alcohol Dependence, 133(3), 805-813. doi:https://doi.org/10.1016/j.drugalcdep.2013.07.027

Helms, J. E. (1984). Toward a theoretical explanation of the effects of race on counseling: A Black and White model. Counseling Psychologist, 12(4), 153-165. doi:10.1177/0011000084124013

Helms, J. E. \& Carter, R. T. (2002). Preliminary scoring information for the WRIAS Social Attitudes Inventory (Revised). Available from the Institute for the Study and Promotion of Race and Culture, Department of Psychology, Boston College, Campion 318, Chestnut Hill, MA, 02467.

Hicks, L. S., Tovar, D. A., Orav, E. J., \& Johnson, P. A. (2008). Experiences with hospital care: Perspectives of Black and Hispanic patients. Journal of General Internal Medicine, 23(8), 1234-1240.

Holley, L. C., Tavassoli, K. Y., \& Stromwall, L. K. (2016). Mental illness discrimination in mental health treatment programs: Intersections of race, ethnicity, and sexual orientation. Community Mental Health Journal, 52, 11-322.

Hook, J. N., Davis, D. E., Owen, J., Worthington Jr, E. L., \& Utsey, S. O. (2013). Cultural humility: Measuring openness to culturally diverse clients. Journal of Counseling Psychology, 60(3), 353-366. 
Horton, J. M. (2015). Exploring the cultural experiences of family case managers: An interpretative phenomenological analysis (Doctoral dissertation). Retrieved from ProQuest Dissertations \& Theses Global.

Hsu, B., Hackett, C., \& Hinkson, L. (2014). The importance of race and religion in social service providers. Social Science Quarterly, 95(2), 393-410.

Huang, B., Appel, H., \& Ai, A. L. (2011). The effects of discrimination and acculturation to service seeking satisfaction for Latina and Asian American women: Implications for mental health professions. Social Work in Public Health, 26(1), 46-59.

Jayaratne, S., Faller, K. C., Ortega, R. M., \& Vandervort, F. (2008). African American and White child welfare workers' attitudes towards policies involving race and sexual orientation. Children \& Youth Services Review, 30(8), 955-966.

Jones, S. (2012). Working with immigrant clients: Perils and possibilities for social workers. Families in Society, 93(1), 47-53.

Jones, L. V., Hopson, L., Warner, L., Hardiman, E. R., \& James, T. (2015). A qualitative study of Black women's experiences in drug abuse and mental health services. Affilia: Journal of Women \& Social Work, 30(1), 68-82.

Joseph, A. L., Slovak, K., Broussard, C. A., \& Webster, P. S. (2012). School social workers and multiculturalism: Changing the environment for success. Journal of Ethnic \& Cultural Diversity in Social Work, 21(2), 129-143.

Kohli, H. K., Huber, R., \& Faul, A. C. (2010). Historical and theoretical development of culturally competent social work practice. Journal of Teaching in Social Work, 30(3), 252-271.

Kraft, G. F. (2011). The relationship between perceived cultural interaction, client 
demographics, and client satisfaction of mental health services providers in the collaborative psychiatric epidemiology survey (2001--2003): An exploratory study (Doctoral dissertation). Retrieved from ProQuest Dissertations \& Theses Global (72).

Lanesskog, D., Piedra, L. M. \& Maldonado, S. (2015). Beyond bilingual and bicultural: Serving Latinos in a new-growth community. Journal of Ethnic \& Cultural Diversity in Social Work, 24(4), 300-317.

Larrison, C. R., Schoppelrey, S. L., Hack-Ritzo, S., \& Korr, W. S. (2011). Clinician factors related to outcome differences between black and White patients at CMHCs. Psychiatric Services, 62, 525-531.

Larson, K. E., \& Bradshaw, C. P. (2017). Cultural competence and social desirability among practitioners: A systematic review of the literature. Children and Youth Services Review, 76, 100-111. doi:10.1016/j.childyouth.2017.02.034

Lawrence, D. A. (2011). The factors impacting the utilization of mental health counseling services by minority male victims of community violence: A qualitative study (Doctoral dissertation). Retrieved from ProQuest Dissertations \& Theses Global (3463166 D.P.H.)

Levac, D., Colquhoun, H., \& O’Brien, K. K. (2010). Scoping studies: Advancing the methodology. Implementation Science, 5, 69.

Lorenzo-Blanco, E., \& Delva, J. (2012). Examining lifetime episodes of sadness, help seeking, and perceived treatment helpfulness among US Latino/as. Community Mental Health Journal, 48(5), 611-626.

Loya, M. (2011). Color-blind racial attitudes in White social workers: A cross-sectional study. Smith College Studies in Social Work (Haworth), 81(2/3), 201-217.

Mancoske, R. J., Lewis, M. L., Bowers-Stephens, C., \& Ford, A. (2012). Cultural competence 
and children's mental health service outcomes. Journal of Ethnic \& Cultural Diversity in Social Work, 21(3), 195-211.

Mason, J. (1995). Cultural competence self-assessment questionnaire: A manual for users. Portland, OR: Research and Training Center on Family Support and Children's Mental Health, Portland State University.

McCoy, M. (2008). Clinical social workers' perspectives on cultural countertransference: A phenomenological study (Doctoral dissertation). Retrieved from ProQuest Dissertations \& Theses Global (AAI3315209).

McGuire, T. G., \& Miranda, J. (2008). New evidence regarding racial and ethnic disparities in mental health: Policy implications. Health Affairs, 27(2), 393-403.

Michalopoulou, G., Falzarano, P., Butkus, M., Zeman, L., Vershave, J., \& Arfken, C. (2014). Linking cultural competence to functional life outcomes in mental health care settings. Journal of the National Medical Association, 106(1), 42-49.

National Association of Social Workers [NASW]. (2017). Code of ethics of the National Association of Social Workers. Retrieved from https://www.socialworkers.org/About/Ethics/Code-of-Ethics/Code-of-Ethics-English

Neville, H. A., Lilly, R. L., Duran, G., Lee, R.M., \& Browne, L. (2000). Construction and initial validation of the Color-Blind Racial Attitudes Scale (CoBRAS). Journal of Counseling Psychology, 47(1), 59-70. http://dx.doi.org/10.1037/0022-0167.47.1.59.

Newhill, C. E., \& Harris, D. (2007). African American consumers’ perceptions of racial disparities in mental health services. Social Work in Public Health, 23(2-3), 107-124.

Pardasani, M., \& Bandyopadhyay, S. (2014). Ethnicity matters: The experiences of minority groups in public health programs. Journal of Cultural Diversity, 21(3), 90-98. 
Parker, H. A. (2014). A qualitative study analyzing CPS social workers: Creating meaning through communication and hidden internal biases (Master's thesis). Retrieved from ProQuest Dissertations \& Theses Global (AAI1562721).

Phillips, F. T. (2010). Social workers' ability to perceive racism, stage of change for actively coping with racism, and observations of health care delivery (Doctoral dissertation). Retrieved from ProQuest Dissertations \& Theses Global (AAI3436217).

Pohan, C. A., \& Aguilar, T. E. (2001). Measuring educators' beliefs about diversity in personal and professional contexts. American Educational Research Journal, 38(1), 159-182.

Ponterotto, J. G., Gretchen, D., Utsey, S. O., Rieger, B. P., \& Austin, R. (2002). A revision of the multicultural counseling awareness scale. Journal of Multicultural Counseling and Development, 30(3), 153-180.

Rastogi, M., Massey-Hastings, N., \& Wieling, E. (2012). Barriers to seeking mental health services in the Latino/a community: A qualitative analysis. Journal of Systemic Therapies, 31(4), 1-17.

Reddick, A. \& Eller, J. (2013). Assessing culturally competent home visitation: Gathering client feedback to evaluate the cultural competency of home visitors and services delivered (Master's Thesis). Retrieved from ProQuest Dissertations \& Theses Global.

Richardson, S. K. (2008). Multicultural competence of Oklahoma department of human services social workers and perceived adequacy of preparation (Doctoral dissertation). Retrieved from ProQuest Dissertations \& Theses Global.

Schlesinger, E. G., \& Devore, W. (1995). Ethnic sensitive social work practice: The state of the art. Journal of Sociology and Social Welfare, 22(1), 29-58.

Scott, L. D., Jr., McCoy, H., Munson, M. R., Snowden, L. R., \& McMillen, J. C. (2011). Cultural 
mistrust of mental health professionals among Black males transitioning from foster care. Journal of Child and Family Studies, 20(5), 605-613.

Spinney, E., Yeide, M., Feyerherm, W., Cohen, M., Stephenson, R., \& Thomas, C. (2016). Racial disparities in referrals to mental health and substance abuse services from the juvenile justice system: a review of the literature. Journal of Crime and Justice, 39(1), 153-173. doi: 10.1080/0735648X.2015.1133492

Stampley, C. D. (2008). Social workers' culture-based countertransferences. Journal of Ethnic \& Cultural Diversity in Social Work, 17(1), 37-59.

Sue, D. W., Rasheed, M. N., \& Rasheed, J. M. (2015). Multicultural social work practice: A competency-based approach to diversity and social justice $\left(2^{\text {nd }}\right.$ ed.). Hoboken, N.J: John Wiley \& Sons, Inc.

Switzer, G. E., Scholle, S. H., Johnson, B. A.,\&Kelleher, K. J. (1998). The client cultural competence inventory: An instrument for assessing cultural competence in behavioral managed care organizations. Journal of Child and Family Studies, 7, 483-491. doi:10. 1023/A:1022910111022.

Taylor, J. S. (2003). The story catches you and you fall down: Tragedy, ethnography, and "cultural competence". Medical Anthropology Quarterly, 17(2), 159-181.

Teasley, M. L., Archuleta, A., \& Miller, C. (2014). Perceived levels of cultural competence for school social workers: A follow-up study. Journal of Social Work Education, 50(4), 694.

Teasley, M., Gourdine, R., \& Canfield, J. (2010). Identifying perceived barriers and facilitators to culturally competent practice for school social workers. School Social Work Journal, 34(2), 90-104.

Terrell, F., \& Terrell, S. (1981). An inventory to measure cultural mistrust among Blacks. The 
Western Journal of Black Studies, 5, 180-185.

Thomas, C. L., Medina, C. K., \& Cohen, H. L. (2010). Latino voices: Service delivery challenges in child protective services. Families in Society, 91(2), 158-164.

Timimi, S. (2010). The McDonaldization of childhood: Children's mental health in neo-liberal market cultures. Transcultural Psychiatry, 47(5), 686-706.

Viruell-Fuentes, E. A., Miranda, P. Y., \& Abdulrahim, S. (2012). More than culture: Structural racism, intersectionality theory, and immigrant health. Social Science \& Medicine, 75(12), 2099-2106.

Wang, Y.W., Davidson, M.M., Yakushko, O.F., Savoy, H.B., Tan, J.A., \& Bleier, J.K. (2003). The Scale of Ethnocultural Empathy: Development, validation, and reliability. Journal of Counseling Psychology, 50(2), 221-234.

Wilkinson-Lee, A., Russell, S. T., \& Lee, F. C. H. (2006). Practitioners' perspectives on cultural sensitivity in Latina/o teen pregnancy prevention. Family Relations, 55(3), 376-389.

Williams, C. C. (2006). The epistemology of cultural competence. Families in Society, 87(2), 209-220.

Williams, S. E., Nichols, Q. L., \& Williams, N. L. (2013). Public child welfare workers' perception of efficacy relative to multicultural awareness, knowledge and skills. Children \& Youth Services Review, 35(10), 1789-1793. 


\begin{tabular}{|c|c|c|}
\hline First Author (Year) & Design/Method & Sample \& Setting \\
\hline Ahn (2014) & $\begin{array}{l}\text { Qualitative: } \\
\text { Interviews }\end{array}$ & $\begin{array}{l}8 \text { migrant parents of children in } \\
\text { mandated therapy; } 4 \text { Korean, } 2 \\
\text { Mexican, } 1 \text { Sudanese, } 1 \text { Albanian. }\end{array}$ \\
\hline Barrio (2008) & $\begin{array}{l}\text { Qualitative: } \\
\text { Focus groups } \\
\text { and interviews }\end{array}$ & $\begin{array}{l}11 \text { Latino elderly clients and } 6 \\
\text { caregivers }\end{array}$ \\
\hline Black (2012) & $\begin{array}{l}\text { Qualitative: } \\
\text { Interviews }\end{array}$ & $\begin{array}{l}60 \text { African American elders who } \\
\text { received healthcare services }\end{array}$ \\
\hline Chang (2009) & $\begin{array}{l}\text { Qualitative: } \\
\text { Interviews }\end{array}$ & $\begin{array}{l}16 \text { racial and/or ethnic minority } \\
\text { clients who received treatment } \\
\text { from } 16 \text { white therapists }\end{array}$ \\
\hline Constantine (2007) & $\begin{array}{l}\text { Mixed methods } \\
\text { Focus groups } \\
\text { and survey }\end{array}$ & $\begin{array}{l}64 \text { African American clients and } \\
19 \text { white counselors ( } 83 \text { total) }\end{array}$ \\
\hline Damashek (2012) & $\begin{array}{l}\text { Quantitative: } \\
\text { Cross-sectional } \\
\text { survey design }\end{array}$ & $\begin{array}{l}1,305 \text { caregivers of children } \\
\text { receiving child welfare services; } \\
70 \% \text { White, } 16 \% \text { American Indian, } \\
8 \% \text { African American }\end{array}$ \\
\hline $\begin{array}{l}\text { Delphin-Rittmon } \\
\text { (2013) }\end{array}$ & $\begin{array}{l}\text { Qualitative: } \\
\text { Focus groups }\end{array}$ & $\begin{array}{l}210 \text { participants: African } \\
\text { Americans ( } 7 \text { focus groups), } \\
\text { Latinos (6), Whites ( } 3), \\
\text { Cambodian (2), and others }\end{array}$ \\
\hline Hicks (2008) & $\begin{array}{l}\text { Qualitative: } \\
\text { Focus groups }\end{array}$ & $\begin{array}{l}37 \text { Hispanic and Black hospital } \\
\text { patients }\end{array}$ \\
\hline Holley (2016) & $\begin{array}{l}\text { Qualitative: } \\
\text { Interviews }\end{array}$ & $\begin{array}{l}20 \text { minority recipients of mental } \\
\text { health service and family members }\end{array}$ \\
\hline Hook (2013) & $\begin{array}{l}\text { Quantitative: } \\
\text { Cross-sectional } \\
\text { survey design }\end{array}$ & $\begin{array}{l}472 \text { college students who had } \\
\text { attended therapy; } 59 \% \text { White, } \\
12.6 \% \text { Black, } 6.6 \% \text { Asian, } 12.8 \% \\
\text { Latino }\end{array}$ \\
\hline Hsu (2014) & $\begin{array}{l}\text { Quantitative: } \\
\text { Cross-sectional } \\
\text { survey design }\end{array}$ & $\begin{array}{l}\text { 2,077 low-income social service } \\
\text { recipients; } 28 \% \text { Hispanic, } 8 \% \\
\text { African American }\end{array}$ \\
\hline
\end{tabular}

Results

Migrant parents encountered discrimination and devaluation in services. Parents who encountered culturally insensitive providers developed negative attitude toward mental health services.

Clients and caregivers experienced language and cultural barriers, lack of information on available services, and scarcity of providers representative of the Latino community.

Participants felt marginalized due to race, gender, and age. They expressed a desire for connectedness with providers by being listened to and having an authentic conversation.

Half of the participants reported satisfying experience in cross-racial therapy, and half did not. Although cultural sensitivity was important (e.g. warmth, caring, selfdisclosure, and being direct), acts of cultural incompetence were more detrimental for the relationship (e.g. minimizing the realities of racial minorities and stereotyping).

Experiences of racial microaggressions by African American clients decreased therapeutic alliance with White therapists and counseling satisfaction and predicted lower ratings of general and cultural counseling competence of the provider.

Higher provider's cultural competence was associated with higher clients' goal attainment and satisfaction with services. Ethnic match predicted goal completion for non-White participants.

Many participants reported satisfaction with services, however, cultural similarity facilitated the development of trust. In general, participants did not discuss race or race-related issues with their providers, and many had experiences where they felt stereotyped, disrespected or dismissed.

Participants highlighted the importance of the availability and quality of translators, and the attitudes of social workers and nursing staff in hospital settings. Black participants experienced negative racial attitudes from hospital support staff.

Participants experienced being ignored and not listened to in mental health services, their identities were often being simplified and rights disrespected, and they were perceived as lacking intelligence. Nevertheless, participants also experienced supportive aspects of services.

Client perception of the provider' cultural humility was positively associated with improvement in therapy and was mediated by strong working alliance.

Having a provider of the same race was very important for African American and Hispanic clients. Having a provider with similar religious beliefs was extremely important for Evangelical Protestants. 
Table 1 Empirical Studies on Client Satisfaction with Multicultural Services

Huang (2011)

Quantitative

Secondary data

analysis: Survey

Jones (2015) Qualitative:

Focus groups

Kraft (2011)

Lawrence (2011)

Quantitative

Secondary data

analysis: Survey

Qualitative:

Interviews

Lorenzo-Blanco

(2012)

Mancoske (2012)

Quantitative

Secondary data

analysis: Survey

Quantitative:

Cross-sectional

survey design

Michalopoulou

(2014)

Newhill (2007)

Quantitative:

Cross-sectional

survey design

Qualitative:

Focus groups

Pardasani (2014)

Quantitative:

Cross-sectional

survey design

Rastogi (2012)

Qualitative:

Focus groups \&

interviews

Reddick (2013)

Quantitative:

Cross-sectional

survey design

Scott (2011)

Quantitative:

Cross-sectional

survey design
188 Latina and 80 Asian American women receiving mental health services (268 total)

29 Black women who received mental health or substance abuse treatment

5,002 clients of mental health services; 49.6\% White, $19.6 \%$

African American, $17.5 \%$ Latino

12 clients of the Violence

Intervention Advocacy Program, and 36 providers, e.g. social workers

2,554 Latino clients of mental health services

111 families with youths who receive mental health services; 81.5\% African-American

94 minority patients in seven mental health clinics; $82 \%$ African Americans.

Five focus groups with African

American mental health consumers (focus groups ranged from 6 to 15)

137 low-income clients receiving healthcare and social services; $37.2 \%$ White, $30.7 \%$ Black, $22.6 \%$ Latino

18 Latino community members, 4 receive mental health services

24 clients receiving home visitation services; $62.5 \%$ Latino, $20.8 \%$ White

74 Black males transitioning from the foster care system
Experiences of gender or race/ethnicity related discrimination decreased the levels of satisfaction with mental health services. Latina and Asian American women were more likely to be satisfied with services if they are older, had more education, had lived in the United States longer, and reported better mental health.

Participants felt that providers tend to generalize black people and ignore issues of race in counseling. The lack of cultural competence in providers created a barrier for participants to develop trust and engage in long-term therapeutic relationships.

Strong relationship was found between provider's level of cultural competence and client satisfaction with mental health services.

Black and Hispanic male victims of community violence were more receptive to counseling services when providers were culturally competent, when stigma of receiving services was reduced, and the symptoms of trauma were normalized.

Discrimination was the strongest predictor of treatment helpfulness; individuals who experienced discrimination found services less helpful.

A statistically significant relationship was found between the provider's cultural competence and better clinical outcomes including assessment, participation, satisfaction, and service outcomes.

Patients' perception of providers' cultural competency was associated with patients' improvements in social interactions, in performance at work or school, and in managing life problems.

Racial and class differences with mental health providers created barriers to communication and feelings of marginalization and alienation. Participants often felt treated in a rushed and impersonal manner.

Latino and Black clients were least likely to report that it was "easy to talk to" staff at the agency and that they were carefully being listened to. White clients were most likely to rate cultural competence of the providers at the highest level. Latino clients reported that the providers did not reflect their racial/ethnic background.

Participants reported difficulty with finding Spanish speaking providers and feared providers may be culturally insensitive and racist. Participants preferred providers who were warm, "personal," direct, and "connected" with their patients.

All of the participants felt their home visitor respected them and their cultural beliefs. Culturally competent practices of the service provider were reflected in the perception of the clients.

Higher satisfaction with the child welfare services was associated with lower cultural mistrust of mental health professionals. 


\begin{tabular}{lll}
\hline First Author (Year) & Design/Method & Sample \& Setting \\
\hline Baranowski (2015) & $\begin{array}{l}\text { Qualitative: } \\
\text { Interviews }\end{array}$ & $\begin{array}{l}\text { 12 mental health practitioners who } \\
\text { with undocumented immigrant clie } \\
\text { social workers, and 6 psychologists } \\
\text { counselors; 50\% Latino, 50\% White }\end{array}$ \\
& $\begin{array}{l}\text { Quantitative: } \\
\text { Cross-sectional } \\
\text { survey design }\end{array}$ & MSW); 76\% White, 10\% Latino \\
& & \\
Bragg (2010) & Quantitative: & 79 licensed social workers, and 86 \\
& Cross-sectional & counselors and marriage and family \\
& survey design & therapists (174 total); $86.5 \%$ White
\end{tabular}

survey design therapists (174 total); $86.5 \%$ White

Brumfield (2013) Mixed method: Survey and focus groups

Bubar (2011) Qualitative:

Interviews

Davis (2012)

Qualitative:

Focus groups

Davis (2015)

Qualitative:

Focus groups

Garran (2008)

Quantitative:

Cross-sectional survey design

Graham (2012)

\section{Qualitative:}

Interviews

Grant (2008) American, 13.8\% White social workers)

56 social workers: 19 from NY who from rural communities in Canada
Quantitative:

Cross-sectional survey design

\section{Results}

Clinician's personal experiences with immigration and ability to speak Spanish was crucial in developing relationship with clients. Clinicians found this work challenging (lack of resources) but rewarding and framed it in social justice terms.

Most practitioners reported receiving social work coursework on practice with immigrants but only $22 \%$ believed they had sufficient knowledge on immigrant issues. Coursework specific to immigration policy, as opposed to practice with immigrants, was associated with more favorable attitudes towards immigrants.

Significant positive relationship was found between mental health providers' personal and professional beliefs about cultural competency. Personal beliefs were not impacted by cultural competence education and training. Those who received cultural competence education and training believed they had higher cultural competence skills.

29 school social workers; $72 \%$ African

15 Multidisciplinary team professionals, e.g. mental health and child welfare providers; 8 Non-Native, 7 people of color, 5 of which identified as Native

The survey results showed "poor" level of cultural competency across the sample. Providers expressed that they would like more multicultural awareness and diversity training.

Participants perceived an overreporting of child sexual abuse in Native populations and underreporting of non-Native sexual abuse cases because of the atmosphere in white communities that try to cover up the issue. The providers believed that Native American culture is often misunderstood and more Native workers are needed in CPS services. The Native professionals often feel powerless and silenced.

The social workers' understanding of cultural competence matched the NASW cultural standards. Cultural competence was perceived as an intentional, active, and ongoing process. Education and professional and personal life experiences contributed to the development of cultural competence.

Providers believed that self-awareness about racism and White privilege are key to effective clinical work, and that it is lifelong growth process. They also stated that it was necessary to address White privilege in clinical conversations and initiate antiracist work in one own circles.

169 white clinical practitioners $(85 \%$ work with Muslim clients, and the rest

Higher clinician abilities related to cultural competence, racial identity, and ethnocultural empathy were associated with a better therapeutic engagement with at risk, urban youth of color.

Providers in both settings reported that social work education has not prepared them for some aspects of practice with diverse groups, particularly in small communities where professional and personal life cannot be easily separated.

Completion of cultural competence trainings was associated with higher levels of cultural competence in the workers. A significant difference was found between minority-governed agencies and non-minority governed agencies in practice that reflects the African American cultural value of childrearing. 
Table 2 Empirical Studies on Providers' Levels of Cultural Competence and Experiences with Multicultural Service Provision

Horton (2015)

Qualitative:

Interviews

white family case managers (3

MSW's, 7 BSW's)

Jayaratne (2008) Quantitative:

Survey

Jones (2012)

Qualitative:

Focus Groups

Joseph (2012)

Quantitative:

Cross-sectional

survey design

Lanesskog (2015) Qualitative:

Interviews

Larrison (2011) Quantitative

Pre- and post-survey

Loya (2011)

McCoy (2008)

Parker (2014)

Qualitative:

Focus Groups,

Interviews

Phillips (2010)
259 providers; $30 \%$ BSW and/or MSW 71\% White, 29\% African American

36 social workers (MSW's) who work with Latino immigrant clients

339 school social workers; $87 \%$ White, 8\% African American

25 human service professionals working with Latinos: social workers, advocates, therapists, etc.; $52 \%$ Latino, $48 \%$ nonLatino

62 mental health professionals $(21 \%$

black) identified by patients as primary clinician, and 551 patients (25\% black) with serious mental illness

179 white social workers

design

21 clinical social workers; $52 \%$ White 43\% African American.

6 social workers; 5 White, 1 Latina

81 social workers; $38.3 \%$ White, $33.3 \%$ African American
Quantitative:

Cross-sectional survey design
Providers found poverty to be the most salient cultural difference in working with families involved in the child welfare system, and most believed in the culture of poverty theory. They supported the belief that all Americans have equal opportunities in life and that hard work would allow the parents raise themselves out of poverty.

African American child welfare workers were more likely than White workers to believe that race should be considered both in general and in placement decisions (racematching seen as important) and that children can be placed in a single parent family.

Providers felt frustrated and caught up in the system which fails to provide services to undocumented immigrants. They believed in social justice and equity and recommended policy changes including legalization. Inability to help their clients led to emotional exhaustion.

90\% of providers reported that their school had a policy against racist jokes and language. Providers reported speaking up when they saw acts of discrimination and took advantage of teachable moments to share cultural knowledge. However, their activities were affected by the school's investment in cultural competency.

Language skills, cultural competence, empathy, and the will to act were necessary for effective service delivery to Latino clients. The workers who possessed these qualities felt frustrated, isolated, and dissatisfied with institutions and colleagues whom they perceived as indifferent to Latino clients' needs.

Treatment outcomes for black and white patients varied depending on the clinician providing the services. Clinician's experiences and relationships with people from racial/ethnic groups other than their own was the only factor predicting the differences.

BSW-level practitioners were found to be less aware of racial privilege and blatant racial issues than MSWs. Providers were very aware of institutional discrimination but had no awareness of racial privilege as well as blatant racial issues.

Providers were often less comfortable, overly curious, or irritated when there was a cultural difference between them and clients. It frequently led to the clients prematurely discontinuing therapy services.

Providers acknowledged the existence of racism within the infrastructure of CPS however, they reported being able to recognize their personal flaws and respecting cultural differences. Being able to effectively work with a culturally diverse family, depended on each case and/or individual social worker.

Social workers were found to have a fairly good ability to recognize racism and or oppression. $50 \%$ of the social workers were in the "maintenance" stage of copying/responding to racism, and $22 \%$ were in either the pre-contemplation or contemplation stage. Non-White social workers were on average in more advanced stage of change for actively coping with racism and/or oppression than Whites. 
Table 2 Empirical Studies on Providers' Levels of Cultural Competence and Experiences with Multicultural Service Provision

$\begin{array}{ll}\text { Richardson (2008) } & \text { Quantitative: } \\ & \text { Cross-sectional } \\ & \text { survey design }\end{array}$

Stampley (2008) Qualitative: Interviews

Teasley (2014)

Quantitative:

Cross-sectional survey design

Teasley (2010)

Thomas (2010)

Williams (2013) Quantitative: Cross-sectional
survey design

\section{Mixed Methods:} Survey and on the survey.

\section{Qualitative:} Focus groups
959 social workers

17 MSW-level social workers; 3 Native American, 3 Asian American, 3 Latinas, 4 African American, 4 White

285 school social workers (97.2\% MSWs) who practice with an urban minority youth; $75 \%$ White, $14 \%$ African American qualitative questions

20 Latino Child Protective Service workers (8 BSW and/or MSW)

260 public child welfare workers (social work or psychology); $40 \%$ African American, 17\% White, 14\% Latino
Social workers were found to have a moderate degree of cultural competence. They reported a moderate to high satisfaction with the multicultural competency preparation they received. The number of multicultural competency courses taken was the best predictors of multicultural competency preparation.

Providers had difficulty identifying clients' strengths and life achievements, and they experienced intrusive and disturbing beliefs, myths, and stereotypes about clients, leading them to distance and avoid certain clients. They often harshly judged the client for not measuring up to their standards and applied their cultural beliefs and values to guide client assessments and to manage the therapeutic relationship.

Majority of providers scored in the middle of cultural competence scores. African American providers and urban and inner-city providers scored significantly higher on cultural competence as compared to whites and those from suburban and rural service areas. Social work education and professional development programs related to cultural competence were significant predictors of cultural competence levels.

Factors facilitating culturally competent practice included: collaboration and assistance from teachers, parental involvement, trainings on cultural competence and knowledge of the practice environment. Barriers to culturally competent practice included: low knowledge and awareness of school social work tasks by school-based personnel's, lack of resources.

Lack of cultural awareness and linguistically and culturally incompetent communication by many CPS staff, and the lack of recognition of the knowledge and skills of the Latino workers were some of the internal barriers. On the systemic level, the workers pointed out there is a general shortage of culturally appropriate services and providers, and inaccessibility of crucial community services.

On average, participants showed good levels of culturally sensitive values and selfawareness in terms of how their thoughts, feelings and interactions with others are being impacted by their cultural background. However, they self-rated themselves as having limited knowledge and skills related to multicultural practice. They also perceived themselves as unaware of culturally specific resources.

Note: 26 studies in total. See the Reference page for full citations of the studies. 